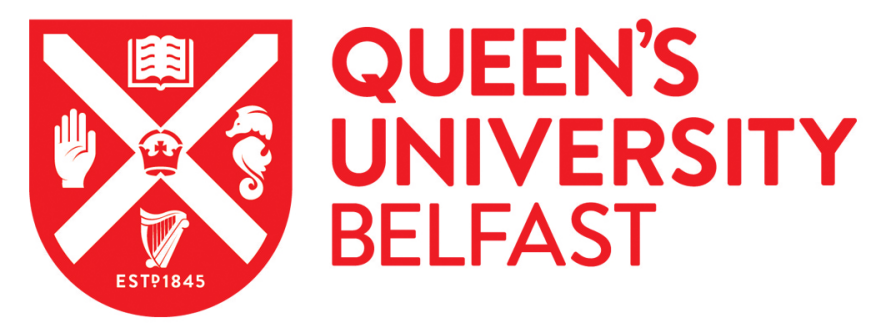

\title{
Delivering social work education on inquiry reports addressing harm to vulnerable people: An exploratory study
}

Houston, S., \& McColgan, M. (2018). Delivering social work education on inquiry reports addressing harm to vulnerable people: An exploratory study. Journal of Social Work, 18(1), 66-84.

https://doi.org/10.1177/1468017316652000

Published in:

Journal of Social Work

Document Version:

Peer reviewed version

Queen's University Belfast - Research Portal:

Link to publication record in Queen's University Belfast Research Portal

Publisher rights

Copyright 2016 The Authors

This work is made available online in accordance with the publisher's policies.

\section{General rights}

Copyright for the publications made accessible via the Queen's University Belfast Research Portal is retained by the author(s) and / or other copyright owners and it is a condition of accessing these publications that users recognise and abide by the legal requirements associated with these rights.

Take down policy

The Research Portal is Queen's institutional repository that provides access to Queen's research output. Every effort has been made to ensure that content in the Research Portal does not infringe any person's rights, or applicable UK laws. If you discover content in the Research Portal that you believe breaches copyright or violates any law, please contact openaccess@qub.ac.uk. 


\section{Delivering Social Work Education on Inquiry Reports Addressing Harm to Vulnerable People: An Exploratory Study}

Summary: This article outlines a research study examining how social work education, in relation to case reviews and inquiry reports, was structured and delivered to a range of social work students in Northern Ireland. Adopting a qualitative design, nine social work educators in the region were interviewed and asked about their approach to presenting findings from the reports to social work students and the issues this raised for the research sample. The results revealed three key themes: the salience of the organizational context; how learning was structured and organized; and the various attempts to build social work competence.

Findings: These themes showed that the co-ordinators were delivering a complex area of knowledge. It was clear that they had given considerable thought to the essential messages from the reports even though the constraints of time and setting were apparent. Moreover, they employed a range of innovations in the way the reports were theorized and how the knowledge coming from them was disseminated. The importance of the 'fear factor' within students was a primary issue affecting teaching and learning strategies.

Applications: The findings can be used as a foundation for further research into this area, looking at student feedback, the attainment of learning outcomes and, importantly, ways of enhancing teaching and learning approaches on this sensitive area. The research can also contribute to the identification of social work educators' learning needs and how to approach emotionally-laden case studies of significant harm to vulnerable individuals.

Key words: social work education, inquiries, case reviews

\section{Introduction}

It is a truism that we live in the risk society (Beck, 1992). Risk, in this context, is a product of globalisation and how it has overturned traditional ways of organising social life. Societal change, on this scale, has invoked a raft of unpredicted effects such as the reorganisation of work and family patterns, accelerating modernisation, the arrival of new pandemics, and different types of terrorism. The notion of risk has also become central in debates about human vulnerability (Kemshall, 2001). More specifically, the social professions now grapple 
daily with the exigent dangers faced by children exposed to acts of abuse and exploitation or vulnerable older people involved in allegations of ill-treatment. When risk leads to severe harm or death, public bodies in English speaking countries tend to respond through structured and systematic inquiries, looking at what went wrong and seeking to learn the lessons' so that future interventions will offer greater safety and protection (Stanley \& Manthorpe, 2004).

When we consider child welfare, in particular, there have been numerous such inquiries or case reviews (Lonne et al, 2008). The same can be said of harms inflicted on vulnerable adults (Mackay, 2004). Some of these inquiries explore multi-disciplinary interfaces. For example, the contiguous boundary between mental health and child protection has been scrutinised (for example, see Western Health \& Eastern Health \& Social Services Boards, 2008). Or the focus has been on institutional harm (Hughes, 1986) or forms of organised abuse (Clyde, 1992). Moreover, some inquiries have concentrated on acts of professional commission (Butler-Sloss, 1988) while others have focused on episodes of omission (Haringey Safeguarding Board, 2009).

In order to present clear messages to the social professions, the range of inquiries and case reviews have been analysed (Cooper, 2005), meta-analysed (Devaney et al, 2013) and theoretically investigated (Rustin, 2005). Core findings have been distilled including the psychological blocks impacting on professionals' recognition of harm; poor communication and inter-agency collaboration; the salience of the caregivers' psycho-biographies (highlighting unmet care and control needs); and exogenous factors such as poverty and social isolation. These findings have been subjected to in-depth scrutiny. For example, Munro (2011) recently argued that the reports had focused inordinately on professional error as opposed to delving below the meniscus of what occurred to identify underpinning causes. To mainly focus on what the professional had failed to do, argued Munro, had led to a blame culture and escalation of the 'fear factor'. To counter these effects, and probe more deeply, she recommended that inquiry panels adopt as systems perspective, taking account of organisational structures and processes.

It is further evident that many inquiry reports make a set of recommendations for training and staff development. In the landmark Hughes Report in Northern Ireland (1986), this took 
the form of a strong plea to professionalise the social work and social care workforce in residential child care. In the Victoria Climbié Report (House of Commons, 2003), training was seen as a means of building confidence in social workers, enabling them to question other disciplinary opinions. Notably, the Cleveland Report (Butler-Sloss, 1988) made a clarion call for inter-disciplinary education and training.

A number of authors have commented on these recommendations for social work education. Rustin (2005), for instance, argued that social workers could benefit from adopting a psycho-dynamic understanding of complex cases of child abuse and neglect, such as occurred in the Victoria Climbié case. For her, dealing with the emotive nature of severe child abuse could lead to defended reactions, mindlessness and mirroring. Ferguson (2005), in a similar vein, examined the psychological aspects of child protection work, noting the significance of transference and counter-transference. According to this commentator, social work education must enable students to understand and reflect on these psychological processes to limit potential blocks to recognition.

Given what has been said, it is vitally important for social work educators to explore this theme with students in a considered, evidence-based and theoretically-informed way. However, we discovered a dearth of empirical research examining this specialist area of knowledge transfer when undertaking a literature search utilising several data-bases (Social Care Online, Scopus, The International Bibliography of the Social Sciences, Sociological Abstracts, The Social Sciences Citation Index) and a range of juxtaposed search terms (for example, 'child abuse inquiry', 'social work education/training', 'adult inquiry', 'case management review', 'serious case review', 'significant case review', 'report'). Even a major review (Moriarty \& Manthorpe, 2013) of the social work qualifying curriculum in England made no reference to the inquiries. Most evaluations of the reports either tended to focus on a content analysis of their findings (for example, Sanders et al, 1999; Reder \& Duncan, 2004; Balen \& Masson, 2008; Devaney et al, 2013) or provided reflective accounts of how such findings impacted on practice. In terms of the latter perspective, Ferguson (2005), for example, contended that the reports should elevate the significance of successful practice rather than lambasting the professionals concerned. A range of other commentators (Reder \& Duncan, 2004; Butler \& Drakeford, 2005; Cooper, 2005) have decried the way some 
reports focused inordinately on structural, organisational and procedural changes at the cost of developing a more holistic set of recommendations around the enhancement of practitioner skills including critical thinking and judgement. Given this state of the knowledge base, we need to know how educational providers organise, deliver and process the curriculum and how it is viewed by the recipients. In this paper, we report on a study comprising semi-structured interviews with a range of relevant module co-ordinators involved in delivering key social work programmes (qualifying and post-qualifying) in Northern Ireland.

\section{Method}

The aim of this study was to ascertain the views of relevant higher education co-ordinators on how their modules tackled the reports' findings and recommendations. More specifically, it sought to appraise their views on the factors influencing their engagement with the area; the approach taken to facilitating learning on this specialist domain of knowledge acquisition; and, as a result of these educational inputs, the issues raised concerning social work knowledge, skills, and values.

To attend to this aim, the study focused on key social work programmes within Northern Ireland where risk, vulnerability, care, protection and safeguarding were essential elements of the curriculum, namely: (i) the two qualifying programmes in the region; (ii) two of the post-qualifying pathways; and (iii) one post-qualifying module. In relation to the qualifying level of training, both universities offered a broadly similar social work curriculum for undergraduate students reflecting their role as partners in the region's 'Social Work Degree Partnership' (a consortium of higher education and agency stakeholders). By way of contrast, the post-qualifying programmes (dealing centrally with safeguarding practices) were more diverse in their focus. They were constituted as a master's level, child care pathway (delivered by Queen's and agency partners); a master's level, mental health pathway (delivered by Queen's and agency partners); and a master's level module in initial professional development (offered by the University of Ulster and agency partners).

The co-ordinators of this provision were then approached purposively to seek their agreement to take part in the research. All in all, nine co-ordinators consented to take part: five affiliated with the University of Ulster and the remainder from Queen's University 
Belfast. This number represented a total sample of co-ordinators delivering modules where the safeguarding of vulnerable individuals was a major theme. Seven out of the nine were male, and all were white. The entire cohort were qualified social workers with a minimum of twenty six years and a maximum of thirty eight years' experience. Four had come mainly from a child care background, the rest mostly from adult services. Similarly, four were primarily engaged at the post-qualifying level, the others with undergraduate modules. Collectively, their role was to plan and organize the curriculum, along with agency partners, deliver the input and evaluate it. Importantly, they took a lead responsibility in deciding which reports were covered, how information concerning them was presented and invariably taught the students directly on some of the attendant themes. Most of the coordinators were experienced social work academics employed by one of the two universities. Two of the co-ordinators, however, were independent social work educators contracted by the universities to deliver the module. They had considerable experience, both in the practice and educational fields, and hence were well qualified to perform their roles.

In-depth, semi-structured interviews were carried out with the sample. This method was chosen because it enabled the researchers to probe important areas, gain an understanding of the key issues, and explore any of the respondents' concerns. The interview schedule loosely covered the following areas: (i) the reports examined and how they were selected; (ii) how teaching on the reports was planned, structured, organised and delivered and by whom; (iii) the factors influencing learning on this topic; (iv) the learning outcomes, knowledge, values, skills and practice issues covered in the sessions; (v) examples of effective teaching methods; and (iv) the areas impacting on the co-ordinators' role and approach. The interview schedule also drew on some of the salient findings arising from the literature. For instance, the researchers were keen to explore how the 'fear factor' amongst the students was managed by the co-ordinators.

The interviews were recorded and transcribed with the respondents' consent. The data was then thematically analysed manually (Howitt, 2010). This process was structured into five sequential stages. First, data familiarization was achieved through reading and re-reading the individual transcripts, noting tentative thoughts. This led to a second stage of attaching 
an initial code to small chunks of the data. Thirdly, moving in the direction of higher abstraction, tentative themes were elicited from the data based on the initial codes in the preceding stage. These themes were subsequently reviewed for accuracy in the fourth stage. This meant returning to the original data and checking the themes against it. Lastly, definite themes were established as a result of refining and reconsidering the analysis. This last stage also necessitated a presentation of the data in a way that was not only accurate, but also accessible for the reader.

\section{Results}

There were 3 overall themes arising inductively from the analysis of the data, namely: (i) the importance of the organizational context; (ii) the focus on learning; and (iii) the development of social work competence (see Figure 1 below).

\section{PLACE FIGURE 1 HERE}

\section{The Importance of the Organizational Context}

This theme reflected the co-ordinators' emphasis on the role of organizations, institutions and bureaucratic bodies in shaping how information from the reports was chosen and presented to the students. It comprised three sub-themes. The first centred on the influence of organizational frameworks. There were two primary examples that were drawn on here: one relating to the region's post-qualifying social work education framework and, the second, referring to the region's requirements for providing the undergraduate social work degree. Both of these sources mapped out how students were meant to progress, the requirements or competences they were expected to meet to gain recognized awards, and the agreed approach to delivering social work education at that level. In terms of the former framework, one post-qualifying module co-ordinator said:

\footnotetext{
'The post-qualifying requirements help to frame what the students need to know and the modules are designed against them. There is no formal needs assessment of the students prior to the module on case management reviews. Areas are selected more by NISCC (Northern Ireland Social Care Council) priorities'. (Respondent 3)
}

Later on, he elaborated on the point: 
'I don't set any specific learning outcomes for information on the case reports and inquiries. I use more overarching post-qualifying ones...about risk, accountability, recording, that sort of thing'.

A co-ordinator on an undergraduate, qualifying module echoed the point, albeit in stronger terms:

'We try to gain an eclectic sense of the students' needs but there is a NISCC straightjacket in what we have to teach even though there is some flexibility'. (Respondent 6)

A second related sub-theme pointed to the corporate, partnership nature of social work education in the region, and how it shaped, inexorably, the planning and delivery of the curriculum, not only in relation to the reports but also as regards its fundamental content. Chiefly, this is was a partnership involving the higher education sector and social work organizations.

As one co-ordinator put it when reflecting on how he planned his module:

\footnotetext{
'I draw on my own understanding and that of subject experts and agency planning groups. But also Departmental requirements. Needs coming out of AYE ('Assessed Year in Practice') with mentors are also fed into the module generally but not specifically in relation to CMRs (Case Management Reviews). This is more about corporate needs assessment than individualized needs assessment. Plus feedback from managers, Trust reps., etc...'. (Respondent 5).
}

As regards this sub-theme, other co-ordinators made reference to the overarching degree systems and structures and Departmental requirements that determined the curriculum including what information to relay about the reports and how to deliver it. To reiterate, then, the organizational context set important parameters, and provided key opportunities and constraints that moulded the co-ordinators' approach to the dissemination of information about the reports. These were 'givens' in the sense of providing foundational prerequisites for curriculum design.

The third sub-theme was strongly related to the preceding one. It centred on regulation and governance. In effect, the co-ordinators were unified in their view that teaching on the reports was meant to strengthen the arms of regulation, governance, and safe practice within agencies. Again, this re-emphasized the overriding significance of the organizational 
context acting as a focal lens through which to view the area. It was one, too, where risk was centre-stage:

'In the last couple of years, I try to get students to think about why CMRs occur, sharing outcomes without getting bogged down into individual context. I now use local inquiries to illustrate broader themes such as the emphasis on clinical social care governance...you're in practice, and this is what we mean by child care governance; how to communicate your concerns; this becomes concrete and real'. (Respondent 2)

Practically, the focus on regulation meant that some modules looked at how professional supervision could be used to accentuate safe practice in risk-laden cases:

'We look at the O'Neill and Toner Reports with their focus on supervision and interagency and interdisciplinary communication. Climbié's focus is on direct contact with service users and the importance of supervision'. (Respondent 2)

For others, there was a danger that educational content might reduce to conveying procedural requirements. Thus, for them, it was vital that discretion, critical thinking and sound practice wisdom were appropriated by students - in addition to meeting organizational imperatives:

'I get the students to look at the McLernon Report. This states that practice is not about following procedures but the importance of individual needs and multidisciplinary communication...we also cover broader themes. The module highlights the importance of not being constrained by bureaucracy plus the importance of judgement and multidisciplinary working. It's a broad brush focus'. (Respondent 7)

\section{The Focus on Learning}

The second theme centred on the co-ordinators' preoccupation with achieving designated learning outcomes. This was an understandable concern given the nature of their role within higher education. In order to realize such outcomes, learning the messages from the various reports had to be intertwined or integrated within the overall social work curriculum. Hence, it was not a matter of teaching a distinct module on the reports' findings but rather embedding them within a range of modules, each with their own specific learning outcomes. Nevertheless, this did not detract from the importance given to this area. 
Under this broad theme, there were three sub-themes emerging from the data. The first concerned the factors impacting on the students' learning, whether deleterious or enabling. For a number of module co-ordinators, various blocks to learning were encountered in some of the students' responses to events depicted in the reports. These blocks could be due to cognitive bias or understandable emotional reactions to the often highly charged material. One co-ordinator said:

'The hindsight error crops up from time to time. You know, 'it was surely obvious to everyone, so why didn't they...'. In the decision-making module, a lot of reassurance is given to try to get them to go beyond blame and to build confidence and to tease out what the learning actually is. We try not to raise the fear factor. The students know this is around, so try not to raise it. We focus on the worst case scenarios. The more attention to this, and the less time spent on context - ie the more time we emphasize it, the more the fear factor will come in. Therefore, we need a measured approach'. (Respondent 8)

A different co-ordinator felt the local nature of some of the reports made some students uncomfortable and less receptive to their messages, particularly if they had personal knowledge of the families concerned:

'There are undoubted sensitivities around the area, for example, O'Neill, it is local. Some care has to be taken as a consequence. Introductions to taught sessions have to be planned. It is important to put a human face on what happened. It is important to allow students not to engage in discussion if they do not feel comfortable or absent themselves'. (Respondent 1)

Interestingly, a third co-ordinator took a different stance on the issue:

'We need to give a health warning when we show some slides....but there is an expectation that students need to know their stuff and not be emotional about it'. (Respondent 3)

A fourth co-ordinator introduced the concept of emotional intelligence when commenting on the emotional domain:

'The emotional aspect is a mine-field. The students' emotional well-being varies. It is hard to fathom emotional intelligence in a large student group. Students may well have mental health difficulties. We don't know much about students' emotional needs nor their degree of emotional intelligence. Students are often shocked by extreme forms of abuse. We sometimes use DVDs which can be very graphic...lecturers have a duty to care for students'. (Respondent 4) 
The salience, and multi-faceted nature, of emotion in this context was revealed in the following observation:

'Emotion comes up a lot. Some students can be very negative about the reports... but they have to take responsibility for their work and avoid this reaction. Some say, "how could this happen, why didn't the social worker see the concern"? Another student got upset on McElhill because of domestic violence in her own family. This is good because honesty is required. I see a lot of anger at social work incompetence and there is a backlash on them. Students can look for the blame game. The doctors got it wrong, not us'. (Respondent 5)

In addition to these cognitive and emotional reactions, there were more practical constraints to learning, specifically relating to the lack of time to cover the reports in detail:

'Time constraints...I only cover a tiny bit of what they need to do; it's the lack of time. They need far more attention to local resources and other material to prompt particular issues, for example, in England, the NSPCC document 'common pitfalls to avoid'. We need to use local examples to Ulsterise it...'. (Respondent 4)

The second sub-theme centred on the degree to which adult learning principles were adopted including how student need, in particular, was appraised. A key factor in all of this was group size. Undergraduate provision targeted large groups of students (sometimes in class sizes of over a hundred students) in comparison to the post-qualifying, post-graduate provision where group size was considerably smaller (between ten and twenty students on average). In the former context, consequently, adult learning was more difficult to achieve. More specifically, it was harder to implement the learning cycle for this group; that is, assessing the students' needs, planning enabling events, then implementing and evaluating them. In many cases, it was down to the co-ordinator to make strategic choices as to which reports were covered and how information concerning them was relayed. Often time, or as previously indicated, group size, prevented a thorough analysis of student need taking place. Without this needs analysis, co-ordinators had to make reasoned decisions about what to teach. For example, one coordinator (of an undergraduate child-care module) described his rationale for selecting which reports to cover as follows:

'Kimberley Carlisle... this was the first major one as it established the child protection system as we know it, ACPCs (Area Child Protection Committees), registers, and the potential for abuse to occur through practice. Jasmine Beckford is also an example of similar conditions to 
Carlisle...these are the emblematic ones. I use Cleveland to illustrate how far the system has moved out of balance, rights not respected, system failed to join up professionals... I cover Kincora as an example of rebalancing'. (Respondent 5)

Tellingly, another co-ordinator said he 'picked up needs through osmosis' (Respondent 6). By this he meant that discussions with students in and out of the classroom, whether formal or informal, revealed a wealth of information about their major preoccupations, concerns, fears and needs. Yet, for him, it was also vital to tune into the organizational context when considering students' learning needs. He felt, in this respect, that the Victoria Climbie report (House of Commons, 2003) had a central relevance to modern day social work as it dealt with fundamental blocks to recognition, poor communication, and inadequate case management.

The third sub-theme reflected various innovations in transmitting learning. One coordinator, for instance, adopted psycho-dynamic theory (Brandell, 2004) to help his students make sense of, on the one hand, the psychological reactions of the social workers embroiled in the events recorded by the reports but also, on the other, their own psychological reactions to learning about these events. Psycho-dynamic theory helps explain inner psychological processes, including the way individuals defend against threatening events and emotions through mechanisms such as transference, counter-transference, repression, splitting and so on:

'I give the students academic papers to read on the inquiry reports which analyse what happened from a psycho-dynamic perspective. Margaret Rustin's and Harry Ferguson's papers...they are really good examples, in the journals. Rustin talks about how the social workers were mindless, you know... a kind of defensive position in the Climbié case. The class then discusses the extent to which this has ever been true for them...what's more, what they ought to do about it. Obviously supervision is a way of picking this up. It's about their countertransference - how they react back against transference from the client when there's risk or unresolved care and control issues...it's a way of helping the students look at their own fear'. (Respondent 9)

Other innovations were more practical and less theoretically informed. One involved the coordinators of the child-care modules on the two undergraduate programmes collaborating closely, even though they were employed by different universities. In effect, they met regularly to jointly plan what to cover and to share resources. More than that, they then 
taught certain sessions on each other's modules: one teaching the theoretical models, the other teaching the policy and procedural context. This ensured consistency of approach within the region.

Another co-ordinator used the idea of getting students to develop poster presentations of what they had learnt from service user inputs and to also incorporate learning from sessions on the reports. He then asked the students to comment on each other's posters. For him, 'this captured many AOP (anti-oppressive practice) themes' and 'enhanced participation'. A number of co-ordinators also emphasized service user involvement in their modules. Often, this did not explicitly address the reports but indirectly engaged with central themes arising from them such as the impact of risk on family life. The co-ordinator of a mental health suite of modules indicated that, 'service users were part of training, planning and evaluation'. A different co-ordinator drew on service user perspectives in relation to the effects of substance abuse (a theme prominent in many of the reports) on family well-being.

Other innovations centred on the use of e-learning, information technology and computerassisted learning:

\footnotetext{
'visual materials are very useful, for example, I put up photographs of Victoria Climbié. These are shown not to shock but to make the point that social work training should encourage social workers to challenge other professionals' views and formulations about alleged abuse to specific children, from example, from the medics. Therefore, that slide shows how the consultant paediatrician accepted the explanation that was given by the caregivers. I also use DVDs...show short clips'. (Respondent 2)

'I give out the actual reports electronically...'. (Respondent 3)

'I present research, through the net and through service users...for example, in relation to children in care, the Trust have a DVD'. (Respondent 7)
}

\section{Developing Social Work Competence}

The last theme addressed the emphasis given to developing social work competence. This concerned a wide range of knowledge, skills and values emanating from the reports' recommendations. We can treat each of these areas as distinct sub-themes. In terms of knowledge, references were made to the law, social policy, theory, and organizational procedures. One co-ordinator drew on theories of object-relations (Cashdan, 1988), 
including attachment theory, to help the students make sense of the family members' psycho-biographies. Such theories address the domain of the inter-personal and how it shapes human identity and psycho-social development. For this co-ordinator, it was important to enable the students to understand 'why these events had occurred' and to 'dig beneath the surface to develop hypotheses about behaviour'. This could only be achieved if the 'students were conversant with explanatory theory'. Systems and ecological theories (Payne, 2014) also played a vital role in ensuring that causal explanations did not only address psychological factors but also social ones:

'There is a heavy emphasis on theory and I get them (the students) to look below the surface, a model which goes beyond the pro-forma into more theoretical frameworks, deep probing into reasons...'. (Respondent 9)

In relation to skills, areas such as communication, observation, relationship-based competence, recording, reporting, challenging others and exerting care and control, were all mentioned:

'There is a focus on the student's language and engagement skills and also the skills of relationship-building that were highlighted in the 'Baby $\mathrm{P}$ ' inquiry. The students' relationshipbuilding skills need developing. There has been a drift to bureaucracy rather than relationship'. (Respondent 8)

One co-ordinator put a lot of emphasis on decision-making as this was a key learning outcome for his module. His focus, here, was on models of decision-making, error, bias, risk assessment, actuarial processes and the use of heuristics. Another co-ordinator spend two days unpacking the subject of risk, addressing how it had been conceptualized in the literature and inquiry reports, and covering models of risk assessment and intervention:

'In the first part of day one, we look at the definition of risk. We then go onto to look at risk factors, what the research has to say, what the students say about it from their experience. Then we cover risk-assessment. I drawn on a model developed by a colleague and apply it to the Jasmine Beckford case. As part of the teaching we also look at what makes for good risk decisions but also look at a thematic analysis of the inquiry reports in the UK'. (Respondent 9)

A number of respondents said there was insufficient time to cover the skills component: 
'skills are covered but they could be more in depth. Values are covered to a better standard than are skills. For example, we need to spend more time of the skills needed to engage resistant families'. (Respondent 6)

'yes, we cover the skill of communication with children but also the time needed for this. But there is no capacity for role play, all we do is lecture...'. (Respondent 6)

'there is not the time to teach directly on the skills implications of the CMRs but in all of the assignments, students must connect with practice'. (Respondent 7)

Most of the respondents had much to say on the subject of values. One co-ordinator used the value-positions framework developed by Fox Harding (1997) to examine taken-forgranted perspectives on some of the families at the centre of the inquiry reports. This framework enabled the students to examine the issues from alternative positions; for example, how might practice have been different if the approach moved from one of childrescue to human rights?

All in all, the focus on enhancing social work competence was meant to not only 'build confidence but also look at what could be done better', as a respondent put it. Furthermore, although the issue of developing competence was stressed, it was underwritten by the message that 'we can't stop the fatalities'. Reassurance was needed to 'counter blame and mitigate the fear factor'. Yet, to enhance competence within students, it was stated that coordinators, too, needed to receive 'up-dated training on the reports'. The fact this was not happening, was seen as a key gap.

\section{Discussion}

Our research suggested that the module co-ordinators were influenced by three formative imperatives, namely: (i) governmental discourses; (ii) academic systems and structures; and (iii) professional and user perspectives (see Figure 2 below). These imperatives emerged from a deeper interpretive interrogation of the themes. In thematic analysis this is permissible and encouraged when it comes to the discussion of the results. Hence, according to Braun and Clarke (2006, p. 97), thematic analysis 'allows for social as well as psychological interpretations of data'.

\section{PLACE FIGURE HERE}


Taking the first imperative, a discourse can be viewed as a discrete area of knowledge, conveyed through talk or writing, comprising a set of inter-linked ideas (Layder, 2006). Discourses shape the way social actors think, the language they use, the actions they perform, and are often constituted by powerful interest groups. The co-ordinators listed these discourses as 'social care governance', 'safeguarding the vulnerable', 'risk management', and 'regulation' (including the codes of social work practice). They were embedded within health and social care policies and procedures in the region including $\mathrm{Co}$ operating to Safeguard Children (DHSSPS, 2003). This policy document delineated the case management systems to be followed to manage risk and regulate the child protection system. A more recent example was the seminal Social Work Strategy (DHSSPS, 2012), a high level policy instrument setting out a vision and agenda for improving and safeguarding the well-being of service users in Northern Ireland. Related to this theme, Martin (2007, p. 265) (a former Chief Inspector of Social Services in Northern Ireland) suggested that, 'the findings from a number of local case management reviews consistently highlighted that procedures or guidance were not being followed and this was not safe practice'.

By way of contrast, academic systems and structures - fixed firmly within higher education institutions - affected the co-ordinator's role in a number of ways. Thus, they had to set designated learning outcomes, and deliver a module that was only a part of a larger congested curriculum (where individual subjects were vying for space). On top of this, were the strictures coming from class size, the availability of university resources, the capacity of teaching rooms, and the parameters attached to timetabling schedules. Reflecting these developments, Balen and Masson (2008, p. 127) argued that, 'for most university staff groups, gone are the days of small class sizes and realistic amounts of time to deliver the social work curriculum'. Realistically, this affected what could be taught on the reports, how and where it was taught and when. The co-ordinators were further subjected to university quality assurance systems which meant they had to think carefully about how the complex messages from the reports were disseminated and judged by the recipients. The lack of time available for this challenging task was most evident. Group size would also determine the capacity to tease out important nuances of meaning. Tutorials might enable this to occur depending on what other pressing topics had to be addressed. Within universities in the UK, 
notably, there has been a change from so called 'light touch' quality assurance (reflecting academic autonomy) to a highly prescribed, audit-led form of control (Hoecht, 2006).

The third imperative came from the need to incorporate important professional and user perspectives within the teaching (Duffy, 2008). This meant the co-ordinators had to be abreast of, not only the recommendations coming from the reports, but also how they connected with the wider social work knowledge base. So, for example, it was interesting to note how connections were made between the literature on culturally-sensitive social work (Houston, 2002; Houston \& Gray, 2015) and those reports dealing with families from a minority ethnic or racial background. Equally, human rights social work appeared to be a pivotal and much rehearsed theme in the teaching.

What is more, the legal and social policy context took on a particular purchase in teaching highlighting social work's statutory functions: child-care and mental health modules being the main repositories of this knowledge. Moreover, as might be expected, the reports raised manifold value-dilemmas which had ramifications for anti-oppressive social work practice (Thompson, 2012). Evidently, it was not just a matter of conveying the learning from the reports, but also trying to explore this learning in the context of social work process; real-life social work at the 'coal-face'; and the development of practice theory. This meant weaving the reports into teaching on mainstream knowledge, skills and values.

The interplay between these three imperatives helps to explain, to a large extent, the thinking and actions of the co-ordinators within this sample. Clearly, they were delivering modules shaped by centralised, 'top-down' directives on social work including the competences that post-qualifying social workers had to meet. The focus on regulation and governance in social work had generated important issues for some of the co-ordinators. In this regard, they were concerned about the emergence of an overly-bureaucratic model of social work. This concern has been widely recognized elsewhere (Payne, 2011) and was highlighted within the seminal Munro Report (2010). Ferguson (2005) critiques the onedimensional, rational-bureaucratic approach in social work that has been fuelled by the inquiries. It was interesting to note the strident call from one co-ordinator to adopt more of a humanistic frame when exploring the reports: one where relationship-based social work (Ruch et al, 2010) was foundational to setting the scene. This example of reflecting on 
underlying 'frames of understanding' is inherent within theories of adult learning (Knowles, 1984).

However, the influence of, and familiarity with, the three imperatives might have hampered the co-ordinators in developing alternative perspectives on the inquiries. Thus, they might have adopted a more critical perspective on the area. For instance, there were no references to the broader political and economic context and how it shaped public and political reactions to violence in the private realm of the family. Under neo-liberalism, the traditional family has been valorised and seen as the institution for socialising its members, providing a haven in a heartless world (Brecher, 2012). It is the unit par excellence affording care and control of children. Violence in the family, as a consequence, becomes a threat to be denounced and fended off. The pressure on families to deliver on these areas is at odds with wider economic realities promulgating austerity measures, cutbacks in benefits and a reduction of prevention and family support (Brecher, 2012). Hence, it is vital that students are aware of this economic context to avoid the danger of pathologizing family members (Munro, 2010).

Despite the afore-mentioned constraints and limitations, it was clear that the co-ordinators were able to shape, in a circumscribed way, how the teaching was delivered. We have referred to this capacity, shown at the centre-point of Figure 2, as the co-ordinators' use of agency. In other words, they could interpret the significance of the various reports for their audience. The various innovations in teaching, described in the results section, bear this out. Moreover, it often seemed the co-ordinators played to their strengths, predilections and interests - showing they could exercise a modicum of choice. The theorization of themes within the reports, by one co-ordinator, through a psycho-dynamic perspective, is a primary example. Another co-ordinator drew on his expertise in social policy to assist students to use a range of alternative value-positions from which they could explore a case. For another co-ordinator, social work assessment was the defining area of knowledge acquisition. The fact that a pair co-ordinators from different universities collaborated closely on their respective modules showed, not only initiative and creativity, but also the licence to cross institutional boundaries. 
That said, it was evident that the co-ordinators felt that much more time, space and resources were needed to cover the reports in the necessary detail. In particular, additional time was required to explore the emotional ramifications of the reports' findings. For them, the 'fear factor' was a palpable and sometimes implacable reality in the classroom and it reaffirms the significance of the emotional domain in safeguarding practices (Ferguson, 2005; Rustin, 2005). In fact, they admitted they were only 'touching the surface' here and this was a significant, if not unexpected, finding. Large classes needed to be complemented by more opportunities for small group work (covering required skills, for instance) and oneto-one tutorials, specifically geared towards exploring the reports in greater detail. Balen and Masson (2008) endorse these methods of knowledge transmission highlighting the need for critical reflection workshops. Moreover, while value-dilemmas were being explored, the constraints of the timetable militated against more probing discussions on this theme.

It was further evident that the region had not produced an integrated learning strategy on the reports to guide the co-ordinators in planning and designing the curriculum. More specifically, it was not clear what learning outcomes the qualifying provision should target as against the follow-on, post-qualifying suite of modules and pathways. It was not evident what messages an early career social worker needed to gain, in particular, as distinct from a final year undergraduate. What messages would a senior manager undertaking a strategy and leadership pathway need to consider and how might they differ from those required by a senior practitioner (a designated role within agencies signifying recognised expertise, experience and capacity to enable the practice of junior colleagues)? A joined up strategy on these areas might have given the co-ordinators a clearer steer on these matters. What is more, the context of the academic systems and structures within which the co-ordinators worked, placed notable constraints upon what could be covered and limited the time available. It was further clear that they were all too aware of the emotional impact of the teaching (a prominent finding in phases one and two): how it could accentuate the 'fear factor'.

There were a number of key limitations in the method. In short, the transfer of learning to practice was not examined nor were objective measures of learning outcomes employed. Moreover, there was the possibility of self-report bias. It might be argued that a sample 
such as this might want to present their approach in the best possible light because of high situational pressures to give professionally desirable answers to a subject area that was considered most sensitive. Yet, the co-ordinators did not depict a sanitised view of their inputs; to reiterate, most felt they were 'only touching the surface' in some areas, particularly when it came to responding to the fear factor: a central reality in the class room. Furthermore, they were open about the fact that skills training was a missing component. Lastly, the research drew on a small sample even though it incorporated all of the module co-ordinators in the region dealing primarily with the subject area. Moreover, despite the limited numbers, the focus was idiographic: one looking for 'thick' descriptions of meaning.

In spite of these limitations in the design, the research generated an important foundation upon which to build subsequent investigations. For instance, we suggest that the results could act as a critical source for an action research project involving the afore-mentioned module co-ordinators in the region, enabling them to further develop their approach to this area through a cyclical set of reflections aimed at enhancing how the reports are taught and considering strategies for measuring impact.

\section{Conclusion}

By way of conclusion, the three overarching themes - addressing the importance of the organizational context, the focus on learning, and the development of social work competence - showed that the co-ordinators were delivering a complex area of knowledge. It was clear that they had given considered thought to the essential messages from the reports even though the constraints of time and setting were apparent. Moreover, they employed a range of innovations in the way the reports were theorized and how the knowledge coming from them was disseminated. A second phase, were it to take place, might attempt to build on this knowledge to enhance the delivery of social work education in this vital area, and we have suggested that an action research project could be the next step. It is clear that this research can only be a starting point for a continuing inquiry into how we protect and safeguard vulnerable children and adults.

There are a number of brief recommendations we can make in addition to ideas about future research. First, we would reiterate the need for an integrated learning and evaluation strategy for the region, setting out tailored learning outcomes for different grades of multi- 
disciplinary staff and different programmes of care. The strategy might also consider ways of measuring the attainment of these learning outcomes, evaluating the impact of teaching on the student's knowledge, skills and values. Different stakeholder groups - students, representatives from lead social work agencies, regulators, users and carers, and higher education institutions - might take this forward through a project management initiative.

Second, we would encourage educators to commit, more fully, to a psycho-dynamic perspective. This would help them, and their students, make sense of the complex processes and relationship lying at the heart of many of the experiences referred to in the class room including the pervasive 'fear factor'. Only a small number of co-ordinators were drawing on this domain of knowledge but, nevertheless, putting it to good effect. Third, we would advise coordinators to find opportunities to reflexively explore their approach to the area, to critically appraise the three imperatives set out above, and consider what alternative perspectives might be drawn on: perspectives excluded by the dominant imperatives. In this context, it is vital to deliberate on the overarching politico-economic context referred to earlier. This reflexive awareness could be facilitated through the suggested action research in a second phase of the study. With recent concerns about the pervasiveness of historic child abuse and exploitation in the UK, and the resurrection of questions about the Kincora affair in Northern Ireland, social work educators need to reflect continuously on their enabling practices in this specialist domain of knowledge transfer.

\section{Ethics}

Ethical approval was granted by Queen's University and the University of Ulster.

\section{Funding}

The study was funded by the Higher Education Authority (UK). 


\section{References}

Balen, R. \& Masson, H. (2008). The Victoria Climbié case: Social work education for practice in children and families' work before and since. Child and Family Social Work, 13(2), 121132. doi : $10.1111 / j .1365-2206.207 .00525 x$

Beck, U. (1992). Risk society. London: Sage.

Brandell, J. (2004). Psychodynamic social work. Columbia: Columbia University Press.

Brecher, B. (2012). The family and neoliberalism: Time to revive a critique. Ethics and Social Welfare, 6(2), 157-167. doi: 10.1080/17496535.2012.682503

Bruan, V. \& Clarke, B.V. (2006). Using thematic analysis in psychology. Qualitative Research in Psychology, 3(2), 77-101. doi: org/10.1191/1478088706qp06oa

Butler-Sloss, E. (1988). Report of the inquiry into child abuse in Cleveland. London: HMSO.

Butler, I. \& Drakeford, M. (2005). Scandal, social policy and social welfare. Bristol: BASW/Policy Press.

Cashdan, S. (1988). Object relations therapy: Using the relationship. London: W.W.Norton.

Clyde, J. (1992). Report of the inquiry into the removal of children from Orkney. Edinburgh: HMSO.

Cooper, A. (2005). Surface and depth in the Victoria Climbié inquiry report. Child and Family Social Work, 10(1), 1-10. doi: 10.1111/j.1365-2006.2005.00350x

Department of Health and Social Services and Public Safety. (2008). Independent review report of agency involvement with Mr Arthur McElhill, Ms. Lorraine McGovern and their children. Belfast: Department of Health Social Services Public Safety.

Department of Health \& Social Services and Public Safety. (2003). Co-operating to safeguard children. Belfast: HMSO. 
Devaney, J., Bunting, L., Hayes, D. \& Lazenbatt, A. (2013). Translating learning into action: An overview of learning arising from case management reviews. Belfast: Queen's University Belfast, NSPCC \& Department of Health, Social Services and Public Safety.

Duffy, J. (2008). Looking out from the middle: user involvement in health and social care in Northern Ireland. London: SCIE.

Ferguson, H. (2005). Working with violence, the emotions and the psycho-social dynamics of child protection. Social Work Education, 24(7), 781-795. doi: org/10.1080/026154705002387oz

Fox Harding, L. (1997). Perspectives in child care policy. London: Routledge.

Haringey Safeguarding Board. (2009). Case review: Baby Peter. London: Haringey Council.

Hoecht, A. (2006). Quality assurance in UK higher education. Higher Education, 51(4), 541563. doi: $10.1007 / \mathrm{s} 10734-0042533-2$

House of Commons (2003). The Victoria Climbié inquiry report. London: The Stationery Office.

Houston, S. (2002). Reflecting on habitus, field \& capital: Towards a culturally-sensitive social work practice. Journal of Social Work, 2(2), 149-167. doi: 10.177/14680173020020003

Houston, S. \& Gray, M. (2015). Falling in love outwards: Eco-social work and the sensuous event. Journal of Social Work (on-line), 1-17. doi: 10.110.1177/146801731581531

Howitt, D. (2010). Introduction to qualitative methods in psychology. Harlow: Pearson Education Limited.

Hughes, W. (1986). Report of the inquiry into children's homes and hostels. Belfast: HMSO.

Kemshall, H. (2001). Risk, social policy and welfare. Buckingham: OU Press.

Layder, D. (2006). Understanding social theory ( $2^{\text {nd }}$ ed.). London: Sage.

Lonne, B., Parton, N., Thomson, S. \& Harries, M. (2008). Reforming child protection. London: Routledge. 
MacKay, J. (2004). Review of the findings of some homicide mental health inquiries since 1994. Mental Health Review, 9(2), 28-30. doi: 10.1108/13619322200400018

Martin, P. (2007). The times they are a changing: The challenges facing social work in Northern Ireland. Child Care in Practice, 13(3), 261-269. doi: 10.1080/13575270701353705

Moriarity, J. \& Manthorpe, J. (2013). Controversy in the curriculum. Social Work Education, 33(1), 77-90. doi: 10.1080/02615479.2012.761689

Munro, E. (2011). The Munro review of child protection: A systems analysis. London: Department of Education.

Payne, M. (2011). Humanistic social work: Core principles in practice. Basingstoke: Palgrave Macmillan.

Reder, P. \& Duncan, S. (2004). Making the most of the Victoria Climbié inquiry report. Child Abuse Review, 13(2), 95-114. doi: 10.1002/car.834

Ruch, G., Turney, D. \& Ward, A. (2010). Relationship based social work: Getting to the heart of practice. London: Jessica Kingsley Publishers.

Rustin, M. (2005). Conceptual analysis of critical moments in Victoria Climbié's life. Child and Family Social Work, 10(1), 11-19. doi: 10.1111/j.1365-2266.2005.00351.x

Sanders, R, Colton, M. \& Roberts, S. (1999). Child abuse fatalities and cases of extreme concern: Lessons from reviews. Child Abuse and Neglect, 23(3), 257-268. doi: 10/1016/s0145-2134(98)00123-9

Stanley, N. \& Manthorpe, J. (2004). The age of the inquiry. London: Routledge.

Thompson, N. (2012). Anti-discriminatory practice: Equality, diversity and social justice (5 $5^{\text {th }}$ ed.). Basingstoke: Palgrave Macmillan.

Western \& Eastern Health \& Social Services Boards. (2008). Report of the independent inquiry panel, Madeleine and Lauren O'Neill. Derry/Belfast: Western Health \& Social Services Board/Eastern Health \& Social Services Board. 